\title{
A STUDY OF ION BINDING IN THE HEMOLYMPH OF PERIPLANETA AMERICANA*
}

\author{
D. J. Weidler and G. C. Sieck \\ Upjohn Center for Clinical Pharmacology, University of Michigan, Ann Arbor, MI U.S.A.
}

(Received 6 April 1976)

\begin{abstract}
The concentrations of the major inorganic ions in the hemolymph of Periplaneta americana were determined as follows (in mM): $\mathrm{Na}^{+}, 132 ; \mathrm{K}^{+}, 8.7 ; \mathrm{Mg}^{2+}, 4.7 ; \mathrm{Ca}^{2+}, 3.7 ; \mathrm{Cl}^{-}, 107 ; \mathrm{PO}_{4}^{3-}$, 1.04 .

2. By the method of ultrafiltration, significant binding to macromolecules in hemolymph was demonstrated for the following ions: $\mathrm{Na}^{+}, 22.0 \% ; \mathrm{Mg}^{2+}, 25.5 \% ; \mathrm{Ca}^{2+}, 16.2 \% ; \mathrm{Cl}^{-}, 10.3 \% ; \mathrm{PO}_{4}^{3-}, 26.9 \%$.

3. $\mathrm{K}^{+}$was not bound significantly to macromolecules in hemolymph.
\end{abstract}

\section{INTRODUCTION}

The concentrations of most of the major inorganic ions in the hemolymph of Periplaneta americana have been reported previously (Tobias, 1948; Duchâteau et al., 1953; van Asperen \& van Esch, 1956; Treherne, 1961; Wendt \& Weidler, 1973). Ion binding in the hemolymph has been investigated in only 2 insect species. Binding to macromolecules was reported for $\mathrm{Ca}^{2+}$ and $\mathrm{Mg}^{2+}$ in Telea polyphemus (Carrington \& Tenney, 1959) and for $\mathrm{Na}^{+}, \mathrm{Ca}^{2+}$, and $\mathrm{Mg}^{2+}$ in $\mathrm{Gal}$ leria mellonella (Plantevin, 1967).

An investigation of ion binding in the hemolymph of $P$. americana is important because of 2 recent findings. First, Pichon (1970) reported that in P. americana the concns of $\mathrm{Na}^{+}, \mathrm{K}^{+}$, and $\mathrm{Ca}^{2+}$ are different in hemolymph samples taken from different regions of the body. Since inorganic ions diffuse relatively rapidly in an aqueous medium, this finding raises the possibility of the binding of inorganic ions to slowly diffusing macromolecules in the hemolymph. Second, there is considerable evidence to support the theory that the ionic composition of the extra-axonal fluid in the nervous system of $P$. americana differs from that of the hemolymph (Treherne \& Moreton, 1970; Treherne \& Pichon, 1972; Treherne et al., 1973; Wendt \& Weidler, 1973; Gardner \& Weidler, 1975); before a reasonable hypothesis can be developed concerning an ionic regulatory system in the nervous system, it is necessary to know the concns of free ions in the hemolymph.

The purpose of the present study was to determine the amount of binding of inorganic ions to macromolecules in the hemolymph of $P$. americana. This objective was achieved in the following way. First, the concns of the major inorganic ions in hemolymph were determined by currently accepted methods. Second, the portions of these concns, which are bound to macromolecules, were determined by ultrafiltration.

* This work was supported in part by USPHS Institutional Research Support Grant FR 5391 and USPHS Institutional Research Support Grant 5P11 GM15559. Reprint requests should be sent to D. J. Weidler, The Upjohn Center for Clinical Pharmacology, The University of Michigan Medical Center, Ann Arbor, MI 48109, U.S.A.

\section{MATERIALS AND METHODS}

Adult male cockroaches of the species, Periplaneta americana, were obtained from our cultures. Their diet consisted of Wayne Lab-blox meal, apples, and tap water ad libitum.

To obtain hemolymph, the unanesthetized roach was held by the anterior thorax and a metathoracic leg was cut off close to the body with a sharp dissecting scissors. Hemolymph wells up at the wound site; the bleeding process is accelerated by both the struggling of the insect and gentle massage of the abdomen. Hemolymph was drawn into capillary tubes (dia $1.5 \mathrm{~mm}$ ) by suction with a syringe. The capillary tubes initially were filled with mineral oil; the continuity of the mineral oil in the capillary tubes was maintained with the mineral oil in the syringe by means of a length of polyethylene tubing. Suction from the syringe moved the mineral oil from the capillary tube into the syringe, the oil being replaced by hemolymph. This method of obtainment of hemolymph was necessary because the hemolymph coagulated rapidly when exposed to air Capillary tubes were filled and sealed with clay at the collecting end; consequently, a column of hemolymph was contained between the oil and the clay plug. This procedure prevented evaporation of the hemolymph during further handling.

After hemolymph collection, the filled capillary tubes were centrifuged for $10 \mathrm{~min}$ in a microcapillary centrifuge (International Equipment Company, Model MB) to separate the hemocytes from the plasma. After centrifugation, the ends of the capillary tubes (one containing the oil drop, and the other containing the clay plug plus the layer of hemocytes) were broken off. The plasma was delivered into small vials which were sealed until chemical determinations could be made.

$\mathrm{Na}^{+}$and $\mathrm{K}^{+}$conens in plasma were determined with a flame photometer (Instrumentation Laboratories, Model 143). Plasma $\mathrm{Cl}^{-}$concns were analyzed with a BuchlerCotlove Chloridometer automatic titrator. $\mathrm{Ca}^{2+}$ and $\mathrm{Mg}^{2+}$ concns were determined with a Perkin-Elmer Atomic Absorption Unit (Model, 290). Phosphate concns were measured using the technique of Goldenberg \& Fernandez (1966).

Because plasma ionic conens were to be compared with ionic concns of the ultrafiltrate, it was necessary to determine the portion of the plasma volume which was occupied by protein. From this information, the ionic concns of the ultrafiltrate were corrected, so that comparisons with plasma ionic concns could be made fairly. To acccomplish this aim, plasma was obtained by the removal of hemocytes from hemolymph as described previously. Subsequently, the plasma was heated in a water bath at a 
temperature of $100^{\circ} \mathrm{C}$ to denature the proteins, and the precipitated proteins were separated out by centrifugation. The vol occupied by the proteins, was measured in a calibrated hematocrit measuring device. A correction factor was determined, and the ionic concns of the ultrafiltrate were multiplied by this factor to correct for the vol which was initially occupied by the proteins.

To measure the degree of ion binding in hemolymph, plasma was subjected to ultrafiltration with a Sorbal Ultracentrifuge (Model 303) at a constant temperature of $25^{\circ} \mathrm{C}$ and at $3000 \mathrm{rev} / \mathrm{min}$. Ultrafiltration was accomplished with cellulose dialyzer tubing, which had a pore size of $4.8 \mathrm{~nm}$; ultrafiltration with this tubing resulted in the retention of molecules with a mol. wt $>12,000$. To avoid evaporation during the ultrafiltration procedure, a saturated humidity was maintained and the ultrafiltrate was collected beneath a layer of mineral oil. After $3 \mathrm{hr}$ of ultracentrifugation, determinations of ionic concns of the ultrafiltrate were made as described previously. The ultrafiltration procedure required a relatively large vol of plasma and it was impossible to determine ionic concns on one insect or even a small number of insects. Therefore, plasma was pooled from 120 roaches; the resultant vol was subjected to ultrafiltration and the ionic concns of the ultrafiltrate were determined. The amount of ion binding was determined by calculating the difference between the initial plasma ionic concns and the corrected ionic conens of the ultrafiltrate.

For statistical analysis of the data, confidence intervals for the means of ionic concns of plasma were calculated at the $0.95,0.99$ and 0.999 levels. If an iunic conon of the ultrafiltrate fell outside of a confidence interval for a given ion, it was interpreted as a significant difference at that level. This approach is valid because the single value for the concn of an ion in the ultrafiltrate was really a mean value (i.e. it was the mean concn from 120 pooled samples). The results of this process were expressed as levels of probability.

\section{RESULTS}

The mean percentage of protein (precipitate) in plasma after heat treatment and centrifugation was $16.8 \pm 2.3$ (mean \pm S.D., $N=7$ ). The range in values was $8-26 \%$. Therefore, the ionic concns of the ultrafiltrate were multiplied by the correction factor of 0.832 before their comparison with the initial plasma concns.

Our determinations of the major inorganic ionic concns in the plasma (i.e. hemolymph from which the hemocytes were removed) and in the ultrafiltrate of plasma in $P$. americana are presented as the mean \pm S.D. in the first 2 lines of Table 1 . The percentages of binding of each ion by macromolecules, which could not pass through the dialyzer membrane, are presented in the last line. Significant binding to macromolecules was found for $\mathrm{Na}^{+}, \mathrm{Mg}^{2+}, \mathrm{Ca}^{2+}$, $\mathrm{Cl}^{-}$, and $\mathrm{PO}_{4}^{3-}$. The binding of $\mathrm{K}^{+}$was not statistically significant.

Since the amount of ion binding in the hemolymph may be altered by a change in the $\mathrm{pH}$, as well as a change in temperature, the $\mathrm{pH}$ of the plasma was measured before and after ultrafiltration. The $\mathrm{pH}$ of plasma initially was 7.17 and the $\mathrm{pH}$ of the ultrafiltrate was 7.10 . It was concluded that the slight change in $\mathrm{pH}$ during ultrafiltration would have no appreciable effect on the amount of ion binding.

\section{DISCUSSION}

It is of interest to compare our determinations of ionic concns in the hemolymph with those reported previously. The phosphate concn of $P$. americana has not been reported previously, and therefore, no comparison can be made. The $\mathrm{Cl}^{-1}$ concn of $107 \mathrm{mM}$ found in the present study for adult male $P$. americana agrees well with the reported concn of $112 \mathrm{mM}$ found in adult female $P$. americana (Wendt \& Weidler, 1973). However, there is an apparent difference between our value for the $\mathrm{Cl}^{--}$concn in the plasma of $P$. americana and the value of $144.3 \mathrm{mM}$ reported by van Asperen \& van Esch (1956). The method of $\mathrm{Cl}^{-}$determination of the latter investigators differed from that used in the present study. Van Asperen \& van Esch chemically precipitated the plasma proteins from hemolymph samples, and determined the $\mathrm{Cl}^{-}$ concn by manual titration. On the other hand, we removed the hemocytes from the hemolymph, but allowed the plasma proteins to remain; then we directly determined the initial $\mathrm{Cl}^{-}$concn with an automatic titrator. The possible reasons for the difference between the $\mathrm{Cl}^{-}$concn reported by van Asperen \& van Esch (1956) and our findings were discussed previously (see Wendt \& Weidler, 1973).

The $\mathrm{Na}^{+}$concn in plasma of $132 \mathrm{mM}$ reported in the present study is lower than the value reported by Pichon \& Boistel (1963) of $163 \mathrm{mM}$, by Pichon (1970) for leg hemolymph of $162 \mathrm{mM}$, or by van Asperen \& van Esch (1956) of $161 \mathrm{mM}$. In the latter 3 studies, the protein was chemically precipitated from the hemolymph. The use of this procedure would be expected to result in a higher $\mathrm{Na}^{+}$concn because the bound $\mathrm{Na}^{+}$would be released; and subsequently, the removal of the precipitated proteins would reduce the vol of a given sample of hemolymph, while the amount of $\mathrm{Na}^{+}$in the sample would

Table 1. Comparison of ionic concentrations of plasma (i.e., hemolymph from which hemocytes were removed) and the ultrafiltrate of plasma from $P$. americana

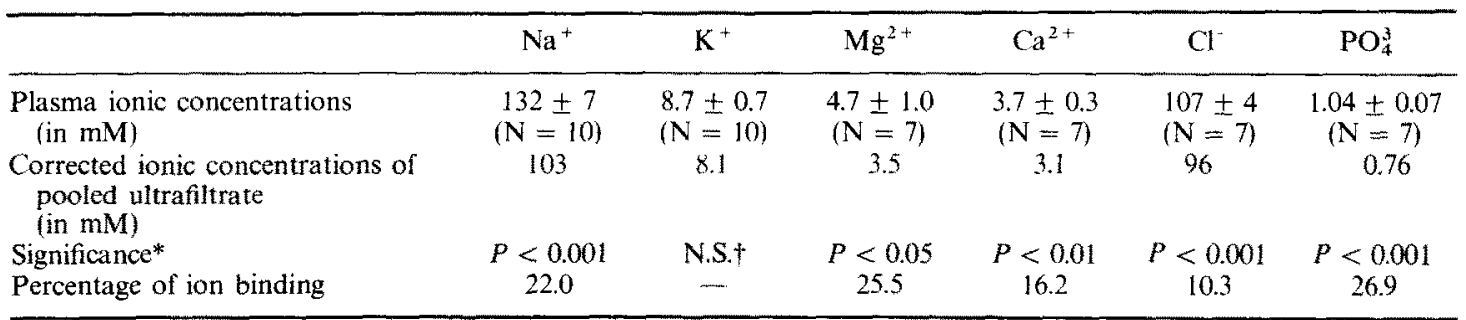

\footnotetext{
* Statistical comparison of the first two lines.
}

$\uparrow$ Not significant. 
remain unchanged. Thus, when $162 \mathrm{mM}$ is multiplied by our factor $0.832, \mathrm{a} \mathrm{Na}^{+}$concn of $134.8 \mathrm{mM}$ is obtained. This agrees well with the $\mathrm{Na}^{+}$concn of $132 \mathrm{mM}$ in the present study.

The $\mathrm{K}^{+}$concn of $8.7 \mathrm{mM}$ found in the present study is close to the value of $8.8 \mathrm{mM}$ reported by Brady (1967) for whole blood $\mathrm{K}^{+}$. However, Brady showed that $10-53 \%$ of the whole blood $\mathrm{K}^{+}$may derive from lysed hemocytes. Pichon \& Boistel (1963) found a value of $24 \mathrm{mM}$, and Pichon (1970) reported a value of $19.5 \mathrm{mM}$. In the latter studies, the hemocytes were not removed and therefore were lysed when the hemolymph was treated with trichloracetic acid to precipitate the proteins. When these factors were considered along with the fact that hemocytes were removed from hemolymph before determinations were made in the present study, the findings in the present study are in good agreement with previous studies.

Our finding of $\mathrm{Mg}^{2+}$ concn of $4.7 \mathrm{mM}$ lies between that reported by Tobias (1948) of $1.7 \mathrm{mM}$ and by van Asperen \& van Esch (1956) of $5.6 \mathrm{mM}$. Similarly, our finding of $\mathrm{Ca}^{2+}$ concn of $3.7 \mathrm{mM}$ is very close to that reported by Pichon (1970) of 3.8 and van Asperen \& van Esch (1956) of $4.3 \mathrm{mM}$.

With one exception, the ions, which are bound to macromolecules in the hemolymph of $P$. americana, are the same as those reported to be bound in other insect species. Thus, significant binding was reported for $\mathrm{Ca}^{2+}$ and $\mathrm{Mg}^{2+}$ in Telea polyphemus (Carrington \& Tenney, 1959) and for $\mathrm{Na}^{+}, \mathrm{Ca}^{2+}$, and $\mathrm{Mg}^{2+}$ in Galleria mellonella (Plantevin, 1967). The latter 2 species also are similar to $P$, americana in that no significant $\mathrm{K}^{\prime}$ ion binding is present. The exceptional ion is $\mathrm{Cl}^{-}$, which is significantly bound in P. americana, but is not bound in Telea polyphemus (Carrington \& Tenney, 1959). To date, a study of phosphate ion binding has not been reported for any insect species; therefore, a comparison cannot be made.

The demonstration of significant binding of $\mathrm{Na}^{+}$ and $\mathrm{Ca}^{2+}$ ions to macromolecules may explain the finding of Pichon (1970) that these ions are unequally distributed in different regions of $P$. americana. Free $\mathrm{Na}^{+}$and $\mathrm{Ca}^{2+}$ ions diffuse relatively rapidly in an aqueous medium, and therefore, the unequal distribution of these ions in the hemolymph is somewhat surprising. As pointed out by Pichon (1970), the hemolymph circulation is rather sluggish, and the movement of hemolymph in certain portions of the insect body is more rapid than in others. Membranes, which act as baffles, deflect the flow of hemolymph during its course of circulation in the insect body. The flow of hemolymph must make relatively sharp turns in the legs and antennae. Under the conditions of low and variable velocity of hemolymph flow and the presence of relatively sharp turns in the course of circulation, macromolecules may be quite unevenly distributed in the circulatory system.

The foregoing statement is supported by certain basic principles of fluid dynamics. The settling out of particles in a fuid depends on the velocity of flow, and the contour and course of the channels (Zenz \& Othmer, 1960). The settling out of particles becomes greater with a decrease in velocity of flow, with a greater inclination of the channel from horizontal and the sharper the bend in the channel; fur- thermore, there is a pile up of particles in recesses or irregularities at bends in the channel as the saltation velocity is approached (Zenz \& Othmer, 1960). The latter phenomenon would apply especially to hemolymph flow in the legs and the antennae. Based on this line of reasoning, the finding of Pichon (1970) that the $\mathrm{Na}^{+}$and $\mathrm{Ca}^{2+}$ concns in hemolymph are higher when sampling is done on the antennae, the legs and the abdomen, than when it is done on the dorsal vessel and the thorax may be at least partially explained by the demonstration in the present study of $\mathrm{Na}^{+}$and $\mathrm{Ca}^{2+}$ ion binding to macromolecules. Other possible factors, which may contribute to an apparent unequal distribution of ions in the hemolymph, previously were presented by Pichon (1970).

The observation that a significant portion of the $\mathrm{Na}^{+}$is bound to macromolecules has implications for the theory that the ionic composition of the extraaxonal fluid differs from that of the hemolymph in $P$. americana (Treherne \& Moreton, 1970; Treherne \& Pichon, 1972; Treherne et al., 1973; Wendt \& Weidler, 1973; Gardner \& Weidler, 1975). Since the evidence seems to indicate that the $\mathrm{Na}^{+}$concn in the extra-axonal fluid is higher than that which has been determined in the hemolymph, the finding of significant $\mathrm{Na}^{+}$binding in the hemolymph indicates that the free $\mathrm{Na}^{+}$gradient from hemolymph to the extra-axonal fluid is even greater than previously considered. Consequently, the potentials, which were measured across the intact neural sheath complex (fat-body, neural lamella, and perineurium), should be reevaluated using the free $\mathrm{Na}^{+}$concn in the hemolymph (see Pichon \& Boistel, 1968), Obviously, the concept of $\mathrm{Na}^{\prime}$ binding would not apply to studies on the intact nerve cord which are done in vitro with an artificial bathing medium. However, in the construction of a theoretical model of ionic regulation in the nervous system of $P$. americana, the free $\mathrm{Na}^{+}$ concn must be used rather than the total $\mathrm{Na}^{+}$concn of the hemolymph. The demonstration of $\mathrm{Na}^{+}$binding in hemolymph tends to support our previously stated hypothesis that some sort of active transport system for $\mathrm{Na}^{+}$is present in the neural sheath complex of the nervous system of $P$. americana (see Wendt \& Weidler, 1973; Gardner \& Weidler, 1975).

In summary, the present work demonstrates that a significant portion of the $\mathrm{Na}^{+}, \mathrm{Mg}^{2+}, \mathrm{Ca}^{2+}, \mathrm{Cl}^{-}$, and $\mathrm{PO}_{4}^{3-}$ concns of the hemolymph of $P$. americana are bound to macromolecules. Consequently, the free concns of these ions are significantly less than the total ionic concns of hemolymph. Significant $\mathrm{K}^{+}$ion binding is not present. The observations reported in the present work partially explain the unequal distribution of ions in the hemolymph, and must be considered in the further development of a theoretical model of ionic regulation in the central nervous system of $P$. americana.

\section{REFERENCES}

BRADY J. (1967) The relationship between blood ions and blood-cell density in insects. $J$. exp. Biol. 47, 313 326 . Carrington C. B. \& Tenney S. M. (1959) Chemical constituents of haemolymph and tissue in Telea polyphemus Cram. with particular reference to the question of ion binding. J. Insect Physiol. 3, 402-413. 
Dúchâtral: G.. Florkix M. \& LFClercQ J. (1953) Concentrations des bases fixes et types de composition de la base totale de l'hémolymph des insectes. Arch. Int. Physiol. 61, 518-549.

Gardner P. J. \& Wridule D. J. (1975) Ultrastructural study of the neural fat-body system in the cockroach Periplaneta americana. Cell Tiss. Res. 159, 485-491.

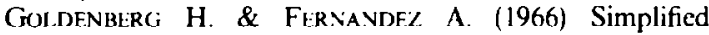
method for the estimation of inorganic phosphorus in hody fluids. Clin. Che'm. 12.871-883.

PICHON Y. (1970) Ionic content of haemolymph in the cockroach. Periplaneta americana. A critical analysis. $J$. exp. Biol. 53, 195209.

PichoN Y. \& BoISTEL J. (1963) Modifications of the ionic content of the haemolymph and of the activity of Periplaneta americana in relation to diet. J. Insect Physiol. 9. 887-891.

Pichon Y. \& Boistel J. (1968) Ionic composition of haemolymph and nervous function in the cockroach, Periplaneta americana L. J. exp. Biol. 49, 31-38.

Pi.antfuiv Gi (1967) Dosige de $\mathrm{Na}^{*}, \mathrm{~K}^{+}, \mathrm{Ca}^{2+}$ et $\mathrm{Mg}^{2+}$ de l'hémolymphe de Galleria mellonella $\mathrm{L}$. par spectrophotometrie de flamme. J. Insect Phy'siol. 13, 1907-1920.

Tobias J. M. (1948) Potassium, sodium and water interchange in irritable tissues and haemolymph of an omni- vorous insect, Periplaneta americana. J. cell. comp. Physiol. 31, 125-142.

TREHFRnE J. E. (1961) Sodium and potassium fluxes in the abdominal nerve cord of the cockroach Periplaneta americana L. J. exp. Biol. 38, 315-322.

TREHERNE J. E. \& MORITON R. B. (1970) The environment and function of invertebrate nerve cells. Int. Rer. Cytol. $28,45-88$

TRFitikNe. J. E. \& PICHON Y. (1972) The insect blood-brain barrier. Adv. Insect Physiol. 9, 257313.

Treher.ne J. E., SChoriel. P. K. \& Lane N. J. (1973) Experimental disruption of the blood-brain barrier system in an insect (Periplaneta americana). J. exp. Biol. 59. $711-723$.

VAX: ASPEREN K. \& VA.N ESCH I. (1956) The chemical composition of the haemolymph in Periplaneta americana. Arch. Neerl. Zool. 11, 342360.

WENDT R. B. \& WIIILLiR D. J. (1973) Effect of externial chloride replacement on action potentials of giant axons in Periplaneta americana. Comp. Biochem. Physiol. 44A. 13031311.

Zf.NZ F. A. \& OThmer D. F. (1960) Fluidization and FluidParticle Systems. Reinhold Publishing Corporation, New York 